\title{
Dermal Collagen and Lipid Deposition Correlate with Tissue Swelling and Hydraulic Conductivity in Murine Primary Lymphedema
}

Joseph M. Rutkowski, ${ }^{\star}$ Carl Erik Markhus, ${ }^{\dagger}$ Christina C. Gyenge, ${ }^{\dagger}$ Kari Alitalo, ${ }^{\ddagger}$ Helge Wiig, ${ }^{\dagger}$ and Melody A. Swartz*

From the Institute of Bioengineering," Ecole Polytechnique Fédérale de Lausanne (EPFL), Lausanne, Switzerland; the Department of Biomedicine, ${ }^{\dagger}$ University of Bergen, Bergen, Norway; and the Department of Molecular Cancer Biology, Haartman Institute, and Helsinki University Hospital, University of Helsinki, Helsinki, Finland

Primary lymphedema is a congenital pathology of dysfunctional lymphatic drainage characterized by swelling of the limbs, thickening of the dermis, and fluid and lipid accumulation in the underlying tissue. Two mouse models of primary lymphedema, the Chy mouse and the K14-VEGFR-3-Ig mouse, both lack dermal lymphatic capillaries and exhibit a lymphedematous phenotype attributable to disrupted VEGFR-3 signaling. Here we show that the differences in edematous tissue composition between these two models correlated with drastic differences in hydraulic conductivity. The skin of Chy mice possessed significantly higher levels of collagen and fat, whereas K14VEGFR-3-Ig mouse skin composition was relatively normal, as compared with their respective wild-type controls. Functionally, this resulted in a greatly increased dermal hydraulic conductivity in K14VEGFR3-Ig, but not Chy, mice. Our data suggest that lymphedema associated with increased collagen and lipid accumulation counteracts an increased hydraulic conductivity associated with dermal swelling, which in turn further limits interstitial transport and swelling. Without lipid and collagen accumulation, hydraulic conductivity is increased and overall swelling is minimized. These opposing tissue responses to primary lymphedema imply that tissue remodelingpredominantly collagen and fat deposition-may dictate tissue swelling and govern interstitial transport in lymphedema. (Am J Pathol 2010, 176:1122-1129; DOI: 10.2353/ajpath.2010.090733)
Primary or congenital lymphedema is a pathological condition in which excess fluid accumulates in the limb because of dysfunctional lymphatic drainage. ${ }^{1,2}$ In humans, primary lymphedema has been linked to mutations in lymphatic endothelial cell genes that result in malformations in lymphatic valve and mural structure or insufficient organization of lymphatic capillaries. ${ }^{3-8}$ As a chronic pathology, lymphedema results in characteristic morphological changes including remodeling of the skin and subcutaneous extracellular matrix (ECM) and accumulation of lipids. ${ }^{9-12}$ Lymphatic function is tightly controlled by the mechanical properties of the tissue via anchoring filaments that attach lymphatic endothelium to the surrounding $\mathrm{ECM},{ }^{13,14}$ such that structural changes can further retard interstitial fluid clearance. ${ }^{11,15}$ No treatment to date can truly restore tissue fluid balance or improve lymphatic function, but there has been success using compression sleeves, massage, and surgical removal of tissue in limiting the pathology. ${ }^{16}$ These successes further underscore lymphedema as not simply a disease of lymphatic transport, but a pathology governed by the ECM.

To recreate the pathology of primary lymphedema in mouse models, lymphatic genes have been targeted to disrupt proper formation of lymphatic vessels during development, but many of these are lethal, including the deletion of Foxc2, ${ }^{3,7}$ VEGFR-3, ${ }^{3,7}$ VEGF-C, ${ }^{17}$ or Prox-1. ${ }^{18}$ Heterozygote mutations or deletions of these genes, however, are sometimes viable and may present poorly formed lymphatic vessels, an edematous phenotype in adulthood, or failed responses to interstitial chal-

Supported in part by the Swiss National Science Foundation (107602) and the European Research Commission (206653-2), the Research Council of Norway, the Norwegian Cancer Society, the Western Norway Regional Health Authority, and the Sigrid Juselius Foundation. C.E.M. was a recipient of a Ph.D. fellowship from the Norwegian Council on Cardiovascular Diseases.

Accepted for publication October 29, 2009.

Address reprint requests to Melody A. Swartz, Ph.D., Institute of Bioengineering, School of Life Sciences/LMBM/Station 15, École Polytechnique Fédérale de Lausanne (EPFL), 1015 Lausanne, Switzerland. E-mail: melody.swartz@epfl.ch. 
lenge..$^{3,7,17-19}$ Although the lymphedema exhibited in such models never entirely recapitulates the extent of swelling of whole limbs or pathological asymmetry found in humans, such models provide an excellent platform for studying the consequential dermal pathology of lymphedema and potential treatments.

The Chy mouse and the K14-VEGFR-3-Ig mouse are two such models previously developed targeting VEGFR-3 signaling. ${ }^{20,21}$ The Chy mouse possesses a heterozygous VEGFR-3 mutation in the tyrosine kinase domain, preventing phosphorylation and resulting in early developmental deficiencies in some lymphatic vessels and chylous ascites as newborns. ${ }^{20}$ Adult Chy mice lack dermal lymphatics. ${ }^{20,22}$ In contrast, the K14-VEGFR3-Ig mouse secretes a soluble variant of VEGFR-3, formed by the fusion of the extracellular ligand-binding domain of VEGFR-3 and an IgG Fc domain, in the epidermis under the keratin-14 (K14) promoter. ${ }^{21}$ The secreted VEGFR-3 appropriates VEGF-C, preventing lymphatic capillary development in the skin. ${ }^{21}$ No abnormal blood vascular phenotypes have been reported in these mice resulting from these mutations. Both mouse models exhibit lymphedema, particularly in the lower limbs, tail, and snout, and tissue histology shows dermal remodeling and fluid accumulation in the hypodermis. ${ }^{20,21}$ Symptomatically, these models represent features of the human disease arising from VEGFR-3 and VEGF-C mutations ${ }^{8}$ and provide a platform for dermal transport consequences in lymphedema.

Interstitial fluid pressure (IFP) provides the driving force for flow through tissues while the hydraulic conductivity $(K)$ of the tissue determines its resistance to flow. Fluid moves more freely through tissues with a higher $K$, potentially limiting the swelling load on the ECM. Factors influencing tissue hydraulic conductivity include tissue hydration, ${ }^{23,24}$ matrix composition, ${ }^{25,26}$ and IFP. ${ }^{27}$ Small changes in matrix composition or IFP can result in large changes to hydraulic conductivity. ${ }^{28}$ We therefore hypothesized that tissue composition changes associated with dysfunctional local lymphatic drainage likely alter tissue hydraulic conductivity and interstitial fluid transport that would dictate the functional manifestation of lymphedema. Tissue collagen, lipid, and water content were measured to determine tissue compositional changes in these mice, and interstitial transport was measured by applying a quantitative in situ model of tissue hydraulic conductivity. Despite both models lacking dermal lymphatics, we found that the tissue compositional changes were quite different between the two models, resulting in large differences in interstitial transport properties. This demonstrates that lymphatic transport deficiencies alone do not determine the extent of lymphedema, but rather that tissue composition plays a critical and potentially compounding influence.

\section{Materials and Methods}

\section{Animals}

Male Chy mice on a $\mathrm{C} 3 \mathrm{H}$ background obtained from the Medical Research Council Mammalian Genetics Unit
Embryo Bank (Harwell, UK), were crossed with wild-type $\mathrm{C} 3 \mathrm{H}$ females to obtain heterozygote Chy offspring. ${ }^{20}$ The Chy mutation was identified by PCR analysis before all experiments using 5'-GAAGACCTTGTATGCTAC-3'/5' AGGCCAAAGTCGCAG-AA-3' primer sequences. ${ }^{22}$ K14VEGFR-3-Ig heterozygote mice on a C57BL/6 background were crossed with wild-type C57BL/6 mice. Offspring were genotyped by PCR using 5'-GAAAGCCCAAAACACTCCAAACAATG-3'/5'-TCCTTGTCTCCGGTGGCTGGCG-3' sequences. ${ }^{21}$ Sixteen- to 24-week-old heterozygotes and their respective wild-type littermates were used for all studies. All studies were approved by the Norwegian State Commission for Laboratory Animals (Protocol \# 2006320) and the Veterinary Authorities of the Canton Vaud according to Swiss law (Protocol \#1987).

\section{Interstitial Fluid Pressure Measurements and Volume Determination}

IFP was measured by micropipettes inserted into the tail skin of anesthesized mice and connected to an automatic counterpressure system as previously described in detail. ${ }^{29}$ After zeroing, measurements were qualified when: (a) the measurement was unaltered with increased feedback gain, (b) suction to the pipette resulted in a resistance change verifying an open capillary, and (c) the zero reference pressure was unchanged. ${ }^{29}$

To determine the differences in tail volumes while avoiding variability attributable to differences in length, the mouse tails were marked $5 \mathrm{~cm}$ from the tip, and the volume of this 5 -cm-length portion was measured by volume displacement in a 5-ml volumetric cylinder. Averages are presented from 5 mice of each type.

\section{Tissue Water and Collagen Composition}

A 2-cm-long piece of intact tail skin was circumferentially excised and the wet weight recorded, then freeze-dried and weighed again for determination of the total tissue water. The freeze-dried sample was then homogenized for collagen determination, which was quantified according to the spectrophotometric method described by Woessner ${ }^{30}$ based on determination of hydroxyproline content as described previously. ${ }^{31}$ The absorbance was read at $557 \mathrm{~nm}$ on a Spectramax Plus384 spectrophotometer (Molecular Devices, Sunnyvale, CA). Hydroxyproline concentration was quantified by comparison with a standard curve of L-4-hydroxyproline (Fluka Chemie GmbH, Buchs, France) in $1 \mathrm{mmol} / \mathrm{L} \mathrm{HCl}$. Collagen content was calculated based on an assumed collagen to hydroxyproline ratio of $6.94 .^{32}$

\section{Immunofluorescence and Histology}

Tail specimens were cut into $10-\mu m$-thick longitudinal cryosections and immunostained. To detect lymphatic endothelium, a rabbit polyclonal antibody against the lymphatic-specific hyaluronan receptor LYVE-1 (Upstate, Charlottesville, VA) was used along with an Alexa Fluor 
488-conjugated goat anti-rabbit secondary antibody (Molecular Probes). To detect blood vessels, a rat polyclonal CD31 antibody (BD Pharmingen) was used with an Alexa Fluor 594-conjugated goat anti-rat secondary antibody (Invitrogen). Cell nuclei were labeled with DAPI (Vector Labs, Burlingame, CA). Sections were fluorescently imaged with a Zeiss Axiovert 200M fluorescence microscope and Zeiss MRm camera.

For histology, sections were first fixed in 4\% PFA. To visualize the matrix, Van Gieson staining was used on both tail cross section and axial sections, which were then dehydrated and mounted with Eukitt (Fluka Chemie AG, Buchs, Switzerland). Oil red O (Sigma-Aldrich, Buchs, Switzerland) was used to stain lipids, with a hematoxylin counterstain, and slides were mounted in Glycergel mounting medium (Dako). Samples were imaged with a Zeiss MRc camera.

\section{Tissue Lipid Analysis}

Lipid content of the tail skin was determined by assessing dry weights before and after fat extraction. Lipid was extracted placing homogenized tail skin samples overnight in $4 \mathrm{ml}$ chloroform and methanol (2:1). The solvent fraction, containing the lipids, was removed and evapo- rated before weighing. This was repeated thrice; the total lipid isolated from 10 to 12 tail samples is reported.

To estimate tissue lipid content from mounted skin sections, Metamorph 6.3 image analysis software (Molecular Devices Corp., Sunnyvale, CA) was used. Five images were captured from each side of the tail of each of five samples. In each, the region between the epidermis and underlying tendon was clearly identified with a freehand tool, and the total oil red $\mathrm{O}$ staining of lipids within this region was quantified per area analyzed.

\section{In Situ Measurement of Tissue Hydraulic Conductivity}

Mice were anesthetized with an intraperitoneal injection of $65 \mathrm{mg} / \mathrm{kg}$ ketamine and $13 \mathrm{mg} / \mathrm{kg}$ xylazine, and the hydraulic conductivity was determined by adapting the technique developed earlier. ${ }^{15}$ Briefly, a 30-gauge needle catheter containing $0.9 \% \mathrm{NaCl}$ with $2 \mathrm{mg} / \mathrm{ml}$ fluorescein-conjugated 70 kDa dextran (Invitrogen, Carlsbad, CA) was carefully placed intradermally into the tail tip. The catheter was attached to a low-pressure reservoir that permitted 5-cm stepwise changes from 40- $\mathrm{cm} \mathrm{H}_{2} \mathrm{O}$ to $60-\mathrm{cm} \mathrm{H}_{2} \mathrm{O}$ pressure. These infusion pressures al-

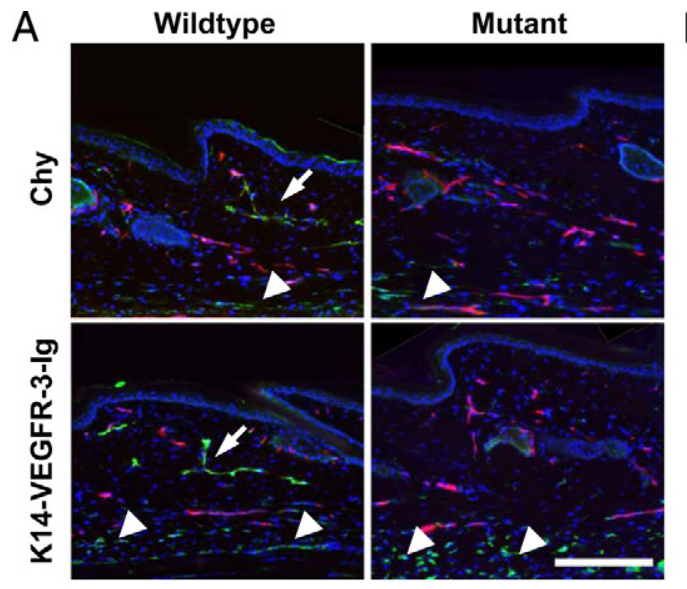

B


Figure 1. Chy and K14-VEGFR-3-Ig mice both display a similar phenotype of dermal lymphedema in terms of absent initial lymphatics, swelling, and heightened interstitial fluid pressure. A: As compared with their respective wild-type controls (left), both Chy (top) and K14-VEGFR-3-Ig (bottom) mice lack dermal lymphatics (arrows; green, LYVE-1). Subdermal LYVE-1+ vessels (arrowheads) are also visible in all mice, presumably marking the collecting lymphatic vessels that run along the major tail veins. The blood vasculature (red, CD31) appeared normal in the dermis of all strains. The dermal thickness is also increased in the model strains. Bar $=200 \mu \mathrm{m}$. B: Lymphatic capillary uptake of fluorescent dextran marked the hexagonal lymphatic dermal network in the mouse tail dermis of wild-type mice (left). No lymphatic transport was observed ahead of the infusion in either mutant tail dermis. Scale bar $=1.0$ mm. C: The edematous tail volume of each model ("Mutant") was significantly increased over that of their respective wild-type controls ("WT"; * $P=0.033$ and *** $P<0.01$, respectively). D: Total tissue water was also significantly elevated in both model strains ( ${ }^{*} P=0.01$ and ${ }^{* *} P=0.05$, respectively). E: In both mouse strains, the measured IFP was significantly higher than their respective wild-type controls $\left({ }^{*} P<0.01\right)$, indicating failure of lymphatic function. 
lowed physiological uptake into the lymphatic capillaries (when present) and postcapillary venules while minimizing potential swelling or tissue damage (as occurs with manual bolus injections in the tail). By measuring the infusion flow rate and the movement of the fluorescent dextran in the interstitial space with pressure, we could estimate the hydraulic conductivity according to the mathematical model developed earlier. ${ }^{15}$ The infusion flow rate was continually monitored via the tracking of a small air bubble introduced into the infusion line; pressures were changed and flow rates monitored for 30 minutes per pressure setting. The volume of the tail tip filled interstitially with the fluorescent tracer was measured at each infusion pressure after 30 minutes using a fluorescence Leica MZ16 FA stereomicroscope or Leica DMR upright fluorescence microscope. Calculations were made according to the theoretical framework outlined previously. ${ }^{15}$ Briefly, we first determined the slopes of the monitored infusion flow rate versus pressure and interstitial infusion volume versus natural logarithm of infusion pressure. These slopes are then multiplied to obtain an interstitial area-dependent hydraulic conductivity which is then corrected by the measured cross-sectional area of the mouse tail. Interstitial area was quantified on tail cross-sections (taken $5 \mathrm{~mm}$ from the tail tip for each animal) with hair follicles, bone, tendon, muscle, etc excluded from the defined area. Cross-sectional areas were also adjusted for the dermal lipid composition as determined by image analysis, because this area was considered to be unavailable to the fluorescent tracer-labeled interstitial fluid. Average baseline tail IFPs were applied as measured to the conductivity calculations for each mouse strain used. Presented values are normalized with respect to their concurrently analyzed wild-type littermates.

\section{Statistical Methods}

For all quantifications representing tissue extractions or animal measurements, at least five animals were used from each group. For quantifications from histochemistry, five samples from each of three animals were analyzed. Data are presented as medians with 95\% confidence intervals. All $P$ values were calculated using a two-tailed Mann-Whitney test.

\section{Results}

\section{Chy and K14-VEGFR-3-Ig Mice Exhibit Increased Dermal Hydration and Interstitial Fluid Pressure}

Immunohistochemical analysis of lymphatic capillaries confirmed the absence of lymphatics in the tail dermis in both the Chy and K14-VEGFR-3-Ig strains as previously described (Figure 1A), ${ }^{20,21}$ and functional lymphatics were not observed when fluorescent dextran was infused into the tail (Figure 1B). Blood capillary density appeared to be normal. As normal lymphatic drainage function is important for maintaining interstitial fluid homeostasis, the lack of initial lymphatics in these models leads to dermal lymphedema, as evidenced by the increased tissue thickness (Figure 1A) and significant increase in tail volume (for $5 \mathrm{~cm}$ end tail length) of $20 \%$ in Chy $(P=0.034)$ and $15 \%$ in K14-VEGFR-3-Ig mice $(P<0.01)$ compared with their respective wild-type strains (Figure $1 C$ ).

Fluid accumulation, or increased tissue hydration, is also a hallmark of the edematous condition resulting from the lack of sufficient lymphatic uptake. Hydration is a key parameter that controls interstitial transport of fluid and solutes. ${ }^{25}$ Total tissue water was measured in the tail dermis of both strains, and interestingly, the dermis of Chy mice exhibited a $25 \%$ increase in tissue water $(P=$ 0.01 ), whereas the K14-VEGFR-3-Ig mice had only $10 \%$ higher $(P=0.05)$ tissue water than their respective wildtype counterparts (Figure 1D).

IFP is a Starling force that regulates tissue hydration through capillary extravasation or uptake. During lymphedema, IFP is increased, ${ }^{22,33}$ shifting the fluid balance so as
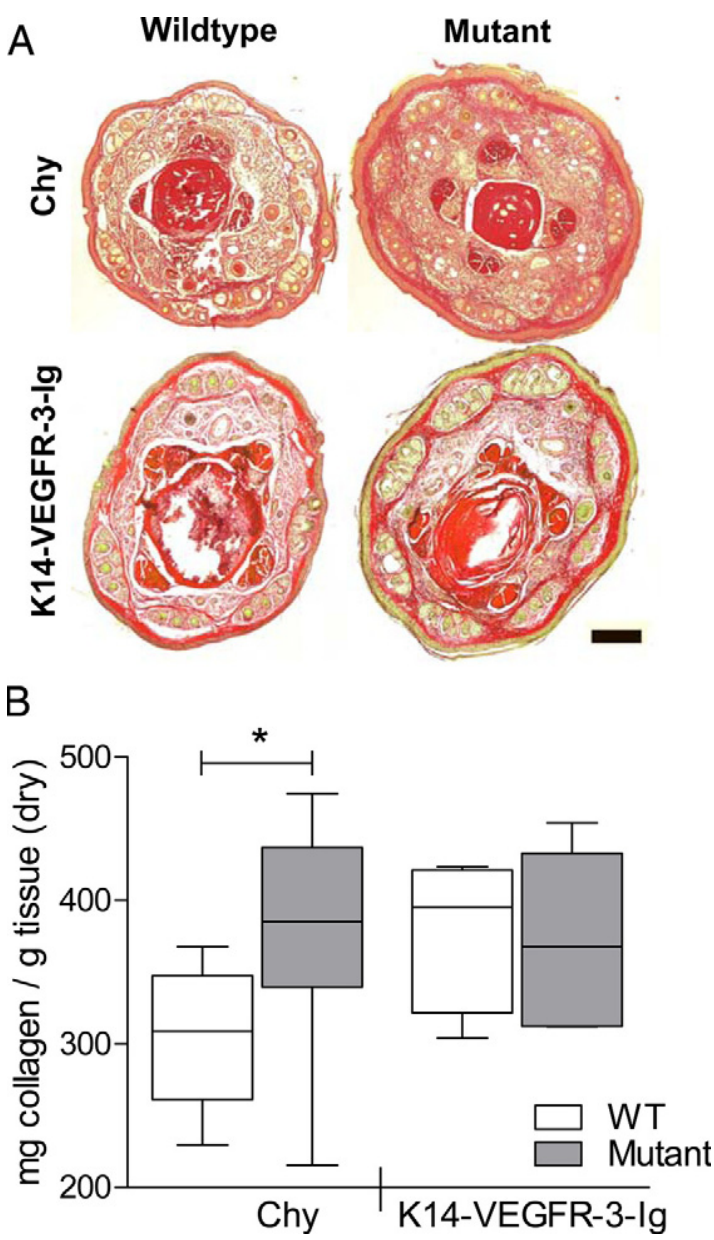

Figure 2. Chy mice, but not K14-VEGFR-3-Ig mice, have increased dermal collagen content. A: Tail cross sections taken $5 \mathrm{~mm}$ from the tail tip and stained with Van Gieson (pink = collagen; red = tendon, bone; yellow = keratin, muscle) display an increased dermal matrix in Chy (top), but not in K14-VEGFR-3-Ig (bottom) mice as compared with their respective wild-type controls. Scale bar $=200 \mu \mathrm{m}$. B: Quantification of dermal collagen content by hydroxyproline determination verifies the increased collagen density in the Chy mouse ( $\left.{ }^{*} P=0.02\right)$ but not the K14-VEGFR-3-Ig mouse as compared with their littermates ("WT"). 
to decrease capillary fluid extravasation; however, with impaired lymphatic drainage, there will be an increased tendency toward swelling in the absence of alterations in $\mathrm{K}$. Consistent with this, we found that the average IFP in the tail skin of both Chy and K14-VEGFR-3-Ig mice was significantly higher than in their wild-type counterparts (both $P<0.01$; Figure 1E).

Chy, but not K14-VEGFR-3-lg, Mice Have More Dermal Collagen and Fat Compared with Wild-Type Controls

Matrix deposition, fibrosis, and lipid accumulation are characteristic of human lymphedema. ${ }^{11}$ These adaptive changes in the tissue structure may be compensatory to the increased IFP in lymphedema and are likely to impact interstitial mechanics and transport. ${ }^{27,34,35}$ Cross-sectional histology of the tails revealed an increase in matrix density in the Chy mouse model over its wild-type mate,

A

A Wildtype
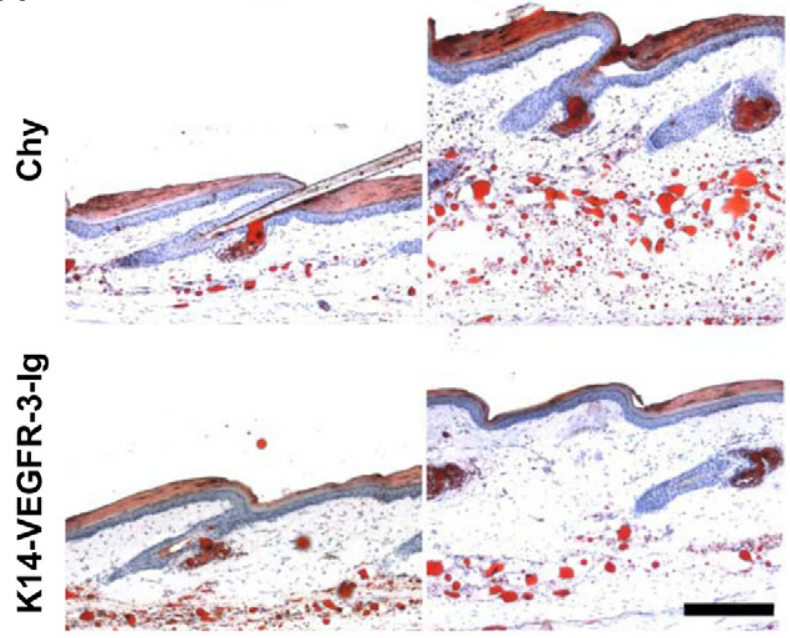

B



Figure 3. Subcutaneous lipid deposition, which is characteristic of human lymphedema, is present in the Chy mouse but not the K14-VEGFR-3-Ig mouse. A: Oil red O staining reveals the lipid accumulation, as compared with wild-type, in the hypodermis of Chy mice (top). K14-VEGFR-3-Ig mice (bottom) did not appear to have significant lipid accumulation. Bar $=200$ $\mu \mathrm{m}$. B: Total tissue lipids extracted from tail dermis quantitatively demonstrate the increase in lipid accumulation within the Chy mouse tail $\left({ }^{*} P=\right.$ 0.034 ) and a quantified decrease in lipids in the K14-VEGFR-3-Ig mouse as compared with their control strains ("WT"; ${ }^{* * *} P=0.013$ ). whereas the K14-VEGFR-3-Ig tissue demonstrated little additional matrix (Figure 2A). Dermal collagen concentrations (on a dry tissue weight basis), as quantified by hydroxyproline assay of tail skin, were significantly higher in Chy mice as compared with their wild-type controls

A



$\mathrm{B}$
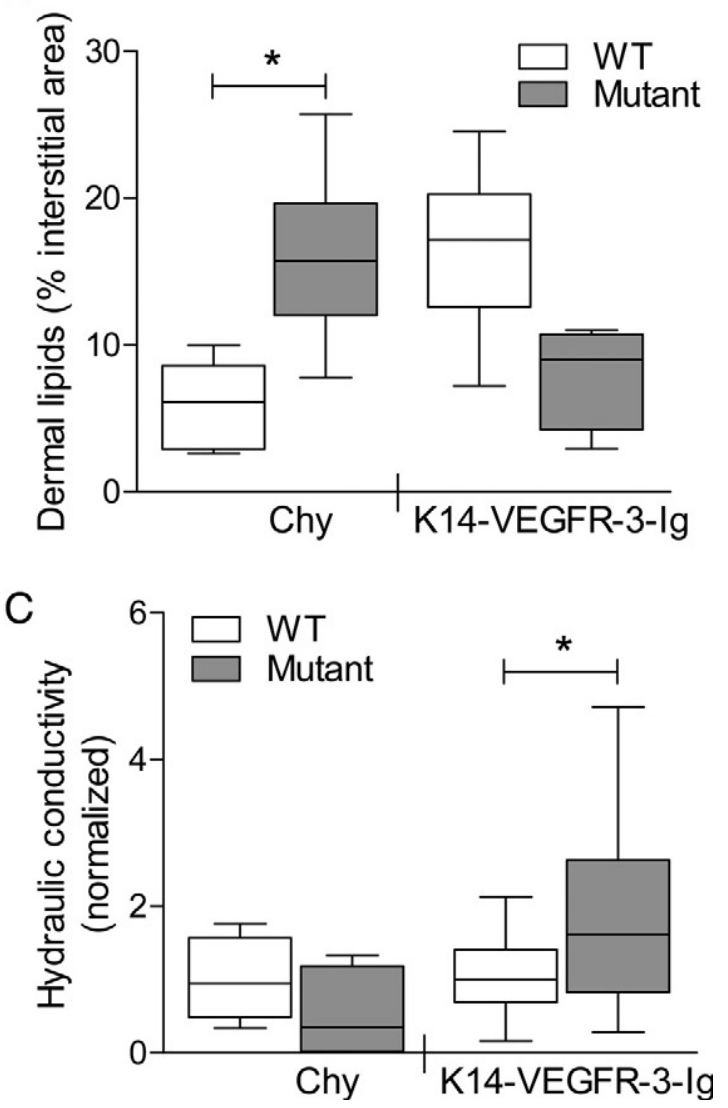

Figure 4. Tissue hydraulic conductivity was increased in K14-VEGFR-3-Ig but not Chy mice. A: Changes in interstitial area were quantified from cross-sectional histology; both mutant models ("Mutant") had larger areas than their respective wild-types ("WT"). B: From histology, the percent interstitial area occupied by lipids was also quantified and reduced from the free interstitial transport area. As in the lipid extractions, Chy mice exhibited a significant increase $\left({ }^{*} P<0.01\right)$. C: Edematous Chy mice exhibited no change in tissue hydraulic conductivity $\left({ }^{*} P=0.21\right.$ ), whereas K14-VEGFR3-Ig mice demonstrated a significant increase in interstitial transport $(P=$ 0.048). Hydraulic conductivity measurements are normalized to the respective WT controls. 
$(P=0.019)$ (Figure 2B). Conversely, K14-VEGFR-3-Ig mice had a collagen content equivalent to that of their controls $(P=0.91)$.

Dermal and subdermal lipid accumulation is another hallmark of lymphedema, ${ }^{2,11,36}$ possibly resulting from failed lymphatic clearance of interstitial lipids. ${ }^{37}$ Lipid accumulation, visualized by oil red $\mathrm{O}$ staining, occurred in the edematous tail skin, most notably in the Chy mouse (Figure 3A). Lipid extraction from tail skin confirmed this: Chy mice had a significant and marked increase in tissue lipid content, over $25 \%$ more $(P=0.034)$, whereas $\mathrm{K} 14$ VEGFR-3-Ig mice had $10 \%$ less lipid content $(P=0.013)$ than respective controls when expressed on a dry weight basis (Figure 3B).

Thus the two mouse strains, both without dermal lymphatics, had adapted very different tissue compositions: the Chy mouse adapted a more collagenous dermis, with an increased presence of lipids, whereas the K14VEGFR-3-Ig mouse did not. We hypothesized that these cumulative tissue differences would impact interstitial fluid transport in these models and therefore have the potential to control the degree of edematous swelling seen in these strains.

\section{K14-VEGFR-3-Ig Mice, but not Chy Mice, Have Elevated Dermal Hydraulic Conductivity}

To measure the changes in hydraulic conductivity of the edematous dermis of Chy and VEGFR-3-Ig mice in situ and in response to intradermal infusions, we used a previously described technique. ${ }^{15}$ To calculate the hydraulic conductivity from interstitial flow measurements, the interstitial cross-sectional area available for interstitial flow in the tails was measured $0.5 \mathrm{~mm}$ from the tail tip. In support of the volumetric tail measurements, both the Chy and K14-VEGFR-3-Ig models had increased subepidermal areas (Figure $4 \mathrm{~A}$ ), although the increases were not significant $(P=0.06$ and $P=0.31$ for Chy and K14-VEGFR-3-Ig, respectively), likely because of the fact that these were at the tip of the tail, which had minimal swelling. Quantification of lipids per unit area in the interstitium was also performed here because the lipid-filled area presents a barrier to interstitial flow. ${ }^{38}$ Chy dermal lipid area was increased as compared with their wild-type littermates $(P<0.01$; Figure 4B), whereas K14-VEGFR3-Ig exhibited a slightly smaller percent lipid area $(P=$ 0.066). These measurements, in conjunction with precise IFP values for each mouse line (Figure 1D), were applied to the described conductivity calculations. ${ }^{15}$
In Chy mice, a higher starting infusion pressure of 50 $\mathrm{cmH}_{2} \mathrm{O}$ (typically beginning at $40 \mathrm{cmH}_{2} \mathrm{O}$ ) was necessary to visibly induce flow into the interstitium. Once flow was established, however, the resultant movement of fluorescent dextran through the matrix was similar to wild-type mice at the same infusion pressure except that no uptake and transport by lymphatic vessels was observed downstream of the infusion (Figure 1B). The average hydraulic conductivity of the Chy mice was not significantly different from that of the wild-type mice $(P=$ 0.21; Figure 4C). In contrast, in K14-VEGFR-3-Ig mice, an initial infusion pressure of $40 \mathrm{cmH}_{2} \mathrm{O}$ was sufficient to induce interstitial flow, despite the higher baseline IFP recorded in these mice. Again factoring in the larger flow area and IFP, the hydraulic conductivity of K14-VEGFR3-Ig was dramatically increased over matching wild-type controls by nearly threefold ( $P=0.026$; Figure $4 \mathrm{C})$. As in the Chy mouse, no lymphatic uptake was visualized in K14-VEGFR-3-Ig mice (Figure 1B).

\section{Discussion}

Though both Chy and K14-VEGFR-3-Ig mice exhibit lymphedema in the skin resulting from lack of dermal lymphatic capillaries, we demonstrated here that the compositional tissue adaptations - namely, lipid and collagen deposition-were markedly different between the models. The physical differences in the dermal tissues consequently impacted the hydraulic conductivities of the skin. Changes in tissue composition demonstrate ways that tissue may adapt with dysfunctional lymphatic clearance (Table 1).

Fluid accumulation in dermis originates from blood capillaries according to Starling forces, ${ }^{39}$ and although most is reabsorbed into postcapillary venuoles, a fraction is normally drained into lymphatic capillaries. Without dermal lymphatics, IFP is increased and interstitial macromolecular concentrations are altered, ${ }^{22,40}$ thus further altering the Starling forces. ${ }^{22,41}$ One compensatory mechanism by which the tissue may adapt is to reduce fluid flux through the interstitium. Indeed, the cumulative changes in the Chy mouse dermis normalized tissue hydraulic conductivity $K$, despite the increased hydration, indicating that the tissue may have adapted in this manner. A recent study in the Chy mouse demonstrated that colloid osmotic pressure in the skin was heightened in these mice and that the interstitial fluid pressure response to volume loading was exaggerated compared

Table 1. Tissue Adaptations in Two Models of Primary Lymphedema

\begin{tabular}{|c|c|c|c|c|}
\hline \multirow[b]{2}{*}{ Measured quantity } & \multicolumn{2}{|c|}{ Chy } & \multicolumn{2}{|c|}{ K14-VEGFR-3-Ig } \\
\hline & Tissue composition & Expected effect on $K$ & Tissue composition & Expected effect on $K$ \\
\hline $\begin{array}{l}\text { Collagen } \\
\text { Water } \\
\text { Fat }\end{array}$ & $\begin{array}{l}\text { Increased } \\
\text { Increased } \\
\text { Increased }\end{array}$ & $\begin{array}{l}\text { Decrease } K \\
\text { Increase } K \\
\text { Decrease } K\end{array}$ & $\begin{array}{l}\text { Normal } \\
\text { Increased } \\
\text { Normal }\end{array}$ & $\begin{array}{l}\text { Neutral } \\
\text { Increase K } \\
\text { Neutral }\end{array}$ \\
\hline $\begin{array}{l}\text { Hydraulic conductivity } \\
\text { Impact on Iymphedema }\end{array}$ & \multicolumn{2}{|c|}{ Neutral } & Increased & $\begin{array}{l}\text { ed } \\
\text { velling }\end{array}$ \\
\hline
\end{tabular}


with that in wild-type mice. ${ }^{22}$ In acute edema (ie, from volume loading of skin and in the absence of remodeling), hydraulic conductivity is known to increase dramatically with increased fluid volume fraction. ${ }^{24,28}$ Presumably, the remodeling in the Chy mouse counteracted that swelling-induced increase in $K$. The heightened collagen and fat density in the Chy dermis could account for these observations.

In the absence of collagen and fat deposition, fluid accumulation in the K14-VEGFR-3-Ig mice indeed led to increased $K$. This in turn counteracts bulk swelling according to the ratio of $K$ to the bulk elastic modulus ${ }^{15}$ that dictates to what extent fluid pressure causes fluid flow versus swelling. Thus, our data suggest that the remodeling occurred in Chy mice to decrease the dermal elasticity and make it easier to swell, whereas in the K14VEGFR-3-Ig mice, tissue $K$ was increased while the bulk elastic modulus was likely unmodified. Increases in conductivity resulting from edematous tissue swelling have also been measured in a mouse tail model of secondary (induced) lymphedema. ${ }^{11,42}$

From an interstitial transport perspective, these mouse models present an intriguing phenomenon. Increased tissue hydration typically leads to a marked increase in hydraulic conductivity $24,25,43$; these parameters are so coupled that linear to even exponential relationships have been demonstrated. ${ }^{24,28}$ Both models exhibit significantly increased tissue hydration, but only the K14VEGFR-3-Ig mouse features a corresponding increase in conductivity. The significantly transformed matrix composition found in the Chy mouse model is likely responsible for the "normal" hydraulic conductivity measured. Changes in matrix composition may further drive adiposity and therefore lipid deposition. ${ }^{44}$ Increases in both matrix protein content ${ }^{25,43,45}$ and lipid content, ${ }^{38}$ as seen in the Chy mouse dermis, are responsible for decreased conductivities. This leads to greater swelling in the Chy mouse dermis than in the K14-VEGFR-3-Ig mouse, in which the tissue is maximally conditioned for fluid transport during the prevailing state of lymphedema.

What drives the specifically different tissue changes across models may be their background strains or individual genetic manipulation. Cross-strain variations in immune cell activity, inflammation, vascular remodeling, and wound healing have been observed, ${ }^{46,47}$ and each of these may influence lymphedema. ${ }^{11,22}$ The fact that these mice compensate sufficiently for a lack of lymphatic drainage may explain why mouse models of congenital lymphedema have, thus far, failed to successfully recapitulate the human condition. Whether it is the baseline propensity of specific tissue compositions or the subsequent remodeling response in these mice that limit lymphedema, for susceptible human patients the pathology may be treatable by targeting the extracellular matrix remodeling.

From a clinical perspective, these results highlight that although lymphedema may be a sufficient blanket term to describe the swelling resulting from insufficient lymphatic transport, the final pathological manifestations are dependent on underlying tissue remodeling that dictates varying tissue effects. The differential response in tissue adaptation discovered in the Chy versus K14-VEGFR3-Ig mouse strains demonstrate the potential for lymphedema to be phenotypically similar yet pathologically and functionally quite different on a case-to-case basis. This suggests that therapies for lymphedema targeting only the growth of new lymphatic vessels or surgical correction of lymphatic ligations may face limited success. Rather, comprehensive therapeutic considerations should also integrate preventing or counteracting collagen and lipid accumulation to restore normal matrix composition and a reduction in adiposity to improve interstitial transport and remediate fluid balance. And for patients in which lymphedema has not yet presented (ie, in cases of lymphedema after surgical lymphatic ligations), maintaining tone and limiting adiposity may also prove to be beneficial.

\section{Acknowledgments}

We thank Bert-Inge Rosengren, Solfrid Olsen, Miriella Pasquier, and Véronique Borel for technical assistance.

\section{References}

1. Connell F, Brice G, Mortimer P: Phenotypic characterization of primary lymphedema. Ann NY Acad Sci 2008, 1131:140-146

2. Warren AG, Brorson H, Borud LJ, Slavin SA: Lymphedema: a comprehensive review. Ann Plast Surg 2007, 59:464-472

3. Dumont DJ, Jussila L, Taipale J, Lymboussaki A, Mustonen T, Pajusola $\mathrm{K}$, Breitman M, Alitalo K: Cardiovascular failure in mouse embryos deficient in VEGF receptor-3. Science 1998, 282:946-949

4. Fang J, Dagenais SL, Erickson RP, Arlt MF, Glynn MW, Gorski JL, Seaver LH, Glover TW: Mutations in FOXC2 (MFH-1), a forkhead family transcription factor, are responsible for the hereditary lymphedema-distichiasis syndrome. Am J Hum Genet 2000, 67:1382-1388

5. Irrthum A, Karkkainen MJ, Devriendt K, Alitalo K, Vikkula M: Congenital hereditary lymphedema caused by a mutation that inactivates VEGFR3 tyrosine kinase. Am J Hum Genet 2000, 67:295-301

6. Karkkainen MJ, Ferrell RE, Lawrence EC, Kimak MA, Levinson KL, McTigue MA, Alitalo K, Finegold DN: Missense mutations interfere with VEGFR-3 signalling in primary lymphoedema. Nat Genet 2000, 25:153-159

7. Petrova TV, Karpanen T, Norrmen C, Mellor R, Tamakoshi T, Finegold D, Ferrell R, Kerjaschki D, Mortimer P, Yla-Herttuala S, Miura N, Alitalo $\mathrm{K}$ : Defective valves and abnormal mural cell recruitment underlie lymphatic vascular failure in lymphedema distichiasis. Nat Med 2004, 10:974-981

8. Verstraeten VL, Holnthoner W, van Steensel MA, Veraart JC, Bladergroen RS, Heckman CA, Keskitalo S, Frank J, Alitalo K, van Geel M, Steijlen PM: Functional analysis of FLT4 mutations associated with Nonne-Milroy lymphedema. J Invest Dermatol 2009, 129:509-512

9. Campisi C, Boccardo F: Lymphedema and microsurgery. Microsurgery 2002, 22:74-80

10. Piller NB: Macrophage and tissue changes in the developmental phases of secondary lymphoedema and during conservative therapy with benzopyrone. Arch Histol Cytol 1990, 53 Suppl:209-218

11. Rutkowski JM, Moya M, Johannes J, Goldman J, Swartz MA: Secondary lymphedema in the mouse tail: lymphatic hyperplasia. VEGF-C upregulation, and the protective role of MMP-9. Microvasc Res 2006, 72:161-171

12. Schirger A, Harrison EG Jr, Janes JM: Idiopathic lymphedema. Review of 131 cases. JAMA 1962, 182:14-22

13. Grimaldi A, Moriondo A, Sciacca L, Guidali ML, Tettamanti G, Negrini D: Functional arrangement of rat diaphragmatic initial lymphatic network. Am J Physiol Heart Circ Physiol 2006, 291:H876-H885

14. Swartz MA: The physiology of the lymphatic system. Adv Drug Deliv Rev 2001, 50:3-20 
15. Swartz MA, Kaipainen A, Netti PA, Brekken C, Boucher Y, Grodzinsky AJ, Jain RK: Mechanics of interstitial-lymphatic fluid transport: theoretical foundation and experimental validation. J Biomech 1999, 32:1297-1307

16. Rockson SG: Diagnosis and management of lymphatic vascular disease. J Am Coll Cardiol 2008, 52:799-806

17. Karkkainen MJ, Haiko P, Sainio K, Partanen J, Taipale J, Petrova TV, Jeltsch M, Jackson DG, Talikka M, Rauvala H, Betsholtz C, Alitalo K: Vascular endothelial growth factor $\mathrm{C}$ is required for sprouting of the first lymphatic vessels from embryonic veins. Nat Immunol 2004, 5:74-80

18. Wigle JT, Oliver G: Prox1 function is required for the development of the murine lymphatic system. Cell 1999, 98:769-778

19. Dellinger MT, Hunter RJ, Bernas MJ, Witte MH, Erickson RP: Chy-3 mice are Vegfc haploinsufficient and exhibit defective dermal superficial to deep lymphatic transition and dermal lymphatic hypoplasia. Dev Dyn 2007, 236:2346-2355

20. Karkkainen MJ, Saaristo A, Jussila L, Karila KA, Lawrence EC, Pajusola K, Bueler H, Eichmann A, Kauppinen R, Kettunen MI, YlaHerttuala S, Finegold DN, Ferrell RE, Alitalo K: A model for gene therapy of human hereditary lymphedema, Proc Natl Acad Sci USA 2001, 98:12677-12682

21. Makinen T, Jussila L, Veikkola T, Karpanen T, Kettunen MI, Pulkkanen KJ, Kauppinen R, Jackson DG, Kubo H, Nishikawa S, Yla-Herttuala S, Alitalo K: Inhibition of lymphangiogenesis with resulting lymphedema in transgenic mice expressing soluble VEGF receptor-3. Nat Med 2001, 7:199-205

22. Karlsen TV, Karkkainen MJ, Alitalo K, Wiig H: Transcapillary fluid balance consequences of missing initial lymphatics studied in a mouse model of primary lymphoedema. J Physiol 2006, 574:583-596

23. Barber BJ, Babbitt RA, Parameswaran S, Dutta S: Age-related changes in rat interstitial matrix hydration and serum proteins. J Gerontol A Biol Sci Med Sci 1995, 50:B282-287

24. Zawieja DC, Garcia C, Granger HJ: Oxygen radicals, enzymes, and fluid transport through pericardial interstitium. Am J Physiol 1992, 262: $\mathrm{H} 136-\mathrm{H} 143$

25. Levick JR: Flow through interstitium and other fibrous matrices. Q J Exp Physiol 1987, 72:409-437

26. Swartz MA, Fleury ME: Interstitial flow and its effects in soft tissues. Annu Rev Biomed Eng 2007, 9:229-256

27. Aukland K, Reed RK: Interstitial-lymphatic mechanisms in the control of extracellular fluid volume. Physiol Rev 1993, 73:1-78

28. Guyton AC, Scheel K, Murphree D: Interstitial fluid pressure. 3. Its effect on resistance to tissue fluid mobility. Circ Res 1966, 19:412-419

29. Wiig H, Reed RK, Aukland K: Micropuncture measurement of interstitial fluid pressure in rat subcutis and skeletal muscle: comparison to wick-in-needle technique. Microvasc Res 1981, 21:308-319

30. Woessner JF, Jr: The determination of hydroxyproline in tissue and protein samples containing small proportions of this imino acid. Arch Biochem Biophys 1961, 93:440-447

31. Reed RK, Lepsoe S, Wiig H: Interstitial exclusion of albumin in rat dermis and subcutis in over- and dehydration. Am J Physiol 1989, 257:H1819-H1827

32. Jackson DS, Cleary EG: The determination of collagen and elastin. Methods Biochem Anal 1967, 15:25-76

33. Bates DO, Levick JR, Mortimer PS: Subcutaneous interstitial fluid pressure and arm volume in lymphoedema. Int J Microcirc Clin Exp 1992, 11:359-373

34. Miserocchi G, Negrini D, Passi A, De Luca G: Development of lung edema: interstitial fluid dynamics and molecular structure. News Physiol Sci 2001, 16:66-71

35. Wiig H, Rubin K, Reed RK: New and active role of the interstitium in control of interstitial fluid pressure: potential therapeutic consequences. Acta Anaesthesiol Scand 2003, 47:111-121

36. Fonder MA, Loveless JW, Lazarus GS: Lipedema, a frequently unrecognized problem. J Am Acad Dermatol 2007, 57:S1-S3

37. Harvey NL, Srinivasan RS, Dillard ME, Johnson NC, Witte MH, Boyd K, Sleeman MW, Oliver G: Lymphatic vascular defects promoted by Prox1 haploinsufficiency cause adult-onset obesity. Nat Genet 2005, 37:1072-1081

38. McCarty WJ, Chimento MF, Curcio CA, Johnson M: Effects of particulates and lipids on the hydraulic conductivity of Matrigel. J Appl Physiol 2008, 105:621-628

39. Rutkowski JM, Swartz MA: A driving force for change: interstitial flow as a morphoregulator. Trends Cell Biol 2007, 17:44-50

40. Bates DO, Levick JR, Mortimer PS: Change in macromolecular composition of interstitial fluid from swollen arms after breast cancer treatment, and its implications. Clin Sci (Lond) 1993, 85:737-746

41. Bates DO, Levick JR, Mortimer PS: Starling pressures in the human arm and their alteration in postmastectomy oedema, J Physiol 1994, 477 (Pt 2):355-363

42. Slavin SA, Van den Abbeele AD, Losken A, Swartz MA, Jain RK: Return of lymphatic function after flap transfer for acute lymphedema. Ann Surg 1999, 229:421-427

43. Znati CA, Rosenstein M, McKee TD, Brown E, Turner D, Bloomer WD Watkins S, Jain RK, Boucher Y: Irradiation reduces interstitial fluid transport and increases the collagen content in tumors. Clin Cancer Res 2003, 9:5508-5513

44. Khan T, Muise ES, Iyengar P, Wang ZV, Chandalia M, Abate N, Zhang BB, Bonaldo P, Chua S, Scherer PE: Metabolic dysregulation and adipose tissue fibrosis: role of collagen VI. Mol Cell Biol 2009, 29:1575-1591

45. Brown EB, Boucher Y, Nasser S, Jain RK: Measurement of macromolecular diffusion coefficients in human tumors. Microvasc Res 2004, 67:231-236

46. Chan CK, Pham LN, Zhou J, Spee C, Ryan SJ, Hinton DR: Differential expression of pro- and antiangiogenic factors in mouse strain-dependent hypoxia-induced retinal neovascularization. Lab Invest 2005, 85:721-733

47. Rajnoch C, Ferguson S, Metcalfe AD, Herrick SE, Willis HS, Ferguson $M W$ : Regeneration of the ear after wounding in different mouse strains is dependent on the severity of wound trauma. Dev Dyn 2003, 226:388-397 